\title{
PELATIHAN MANAJEMEN PROYEK DENGAN METODE CPM (Critical Path Method) DI PT. NIROMUKTI AIRTECH INDONESIA
}

\author{
Tulus Widjajanto ${ }^{1}$ Surya Perdana ${ }^{2}$, Arif Rahman ${ }^{3}$

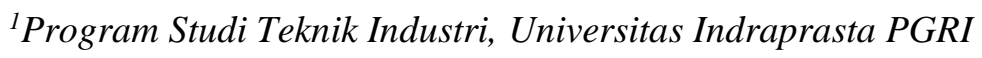 \\ tulus_wijayanto@yahoo.com \\ ${ }^{2}$ Program Studi Teknik Industri, Universitas Indraprasta PGRI \\ suryaperdana.st.mm@gmail.com \\ ${ }^{3}$ Program Studi Teknik Industri, Universitas Indraprasta PGRI \\ arif.rahman0908@yahoo.com
}

\begin{abstract}
This activity aims to provide understanding to employees of PT. Niromukti Airtech Indonesia regarding Project Management with the Critical Path Method (CPM) method to add insight into understanding the CPM concept well and apply it to running a project. The output of this activity is to produce a module on Project Management with the Critical Path Method (CPM) Method. The method carried out in the implementation of the abdimas is divided into two stages, in the first stage direct observation is carried out, namely: the abdimas team comes to the location directly in order to obtain data. This is done both before and during the activity. The second stage is Counseling, namely: the serving team teaches and explains directly about the subject matter of Project Management with the Critical Path Method (CPM) method for employees to get additional insight into understanding the CPM concept. Teaching is conducted 3 times face to face so that the trainees at PT. Niromukti Airtech Indonesia is better prepared to carry out a project.
\end{abstract}

KeyWords: Project Management, Critical Path Method (CPM)

\begin{abstract}
Abstrak : Kegiatan ini bertujuan untuk memberikan pemahaman kepada para karyawan PT. Niromukti Airtech Indonesia mengenai Manajemen Proyek dengan Metode Critical Path Method (CPM) untuk menambah wawasan memahami konsep CPM dengan baik dan mengaplikasikannya dalam menjalankan suatu proyek. Target luaran kegiatan ini adalah menghasilkan modul tentang Manajemen Proyek dengan Metode Critical Path Method (CPM). Metode yang dilakukan dalam pelaksanaan abdimas dibagi menjadi dua tahapan, pada tahap pertama dilakukan observasi langsung, yaitu: tim abdimas datang ke lokasi langsung dalam rangka memperoleh data. Hal ini dilakukan pada saat menjelang maupun pada saat kegiatan berlangsung. Tahap kedua adalah Penyuluhan, yaitu: tim pengabdi mengajarkan dan menerangkan secara langsung perihal materi Manajemen Proyek dengan Metode Critical Path Method (CPM) kepada karyawan guna mendapatkan tambahan wawasan memahami konsep CPM. Pengajaran dilakukan 3 kali tatap muka agar peserta pelatihan di PT. Niromukti Airtech Indonesia menjadi lebih siap dalam menjalankan suatu proyek.
\end{abstract}

Kata Kunci : Manajemen Proyek, Critical Path Method (CPM)

\section{PENDAHULUAN}

Dalam kehidupan sehari-hari banyak ditemui berbagai macam proyek yang harus dikerjakan dengan baik. Demi kelancaran keberlangsungan suatu proyek dibutuhkan manajemen proyek yang akan mengelola proyek tersebut mulai dari awal sampai proyek tersebut berakhir. Dalam manajemen proyek seringkali dijumpai proyek-proyek berbentuk jaringan yang berskala besar. Untuk mengadakan perencanaan dan pengendalian proyek yang berjenis jaringan tersebut, seorang manajer perlu menentukan kegiatan-kegiatan kritis yang sangat mempengaruhi penyelesaian suatu proyek. Perencanaan kegiatan proyek merupakan masalah yang sangat penting karena hal tersebut merupakan dasar suatu proyek dapat berjalan dengan lancar dan dapat selesai dengan waktu yang optimal.

Dalam suatu kondisi pemilik proyek dapat saja menginginkan proyek selesai lebih awal dari rencana semula dengan alasan percepataan penyelesaian suatu proyek atau karena faktor eksternal seperti misalnya faktor cuaca, yang membuat proyek memiliki perkembangan yang 
buruk sehingga implementasi proyek tidak berjalan seperti yang direncanakan, atau dapat dikatakan kemajuan proyek lebih lambat. Untuk mengembalikan tingkat kemajuan proyek ke rencana semula diperlukan suatu upaya percepatan durasi proyek yang diikuti meningkatnya biaya proyek. Perlunya analisis optimalisasi durasi proyek untuk dapat mengetahui berapa lama suatu proyek tersebut diselesaikan secara optimal. Untuk mencari adanya kemungkinan percepatan waktu pelaksanaan proyek tersebut, manajemen proyek dapat menggunakan metode PERT dan CPM (Critical Path Method) untuk penyelesaian proyek tersebut.

CPM dan PERT dapat digunakan dalam perencanan dan pengendalian proyek. Misalnya dalam proyek Pemerintah yang akan membangun rumah sakit berstandar internasional, apa saja kegiatan untuk membangun rumah sakit tersebut, dan kapan jadwal dan pengendalian proyek tersebut agar selesai tepat waktu serta berapa biaya yang digunakan dapat jelas apabila menggunakan metode PERT dan CPM. Kedua-duanya mendeskripsikan aktifitas-aktifitas proyek dalam jaringan kerja, dari jaringan kerja tersebut mampu dilakukan berbagai analisis untuk pengambilan keputusan tentang waktu, biaya, serta penggunaan sumber daya dan bertujuan untuk sebanyak mungkin mengurangi adanya penundaan, maupun gangguan produksi, serta mengkoordinasikan berbagai bagian suatu pekerjaan secara menyeluruh dan mempercepat selesainya proyek. Maka dari itu kami membuat makalah yang membahas tentang PERT dan CPM serta aplikasinya.

Proyek dalam analisis jaringan kerja adalah serangkaian kegiatan-kegiatan yang bertujuan untuk menghasilkan produk yang unik dan hanya dilakukan dalam periode tertentu (temporer) (Maharesi, 2002). Proyek dapat didefinisikan sebagai suatu rangkaian kegiatan yang hanya terjadi sekali, dimana pelaksanaannya sejak awal sampai akhir dibatasi oleh kurun waktu tertentu (Tampubolon, 2004). Menurut Soeharto (1999, h.2) : Kegiatan proyek dapat diartikan sebagai satu kegiatan sementara yang berlangsung dalam jangka waktu terbatas, dengan alokasi sumber daya tertentu dan dimaksudkan untuk menghasilkan produk atau deliverable yang kriteria mutunya telah digariskan dengan jelas. Munawaroh (2003) menyatakan proyek merupakan bagian dari program kerja suatu organisasi yang sifatnya temporer untuk mendukung pencapaian tujuan organisasi, dengan memanfaatkan sumber daya manusia maupun non sumber daya manusia.

Menurut Subagya (2000) : Proyek adalah suatu pekerjaan yang memiliki tanda-tanda khusus sebagai berikut, yaitu,

1. Waktu mulai dan selesainya sudah direncanakan.

2. Merupakan suatu kesatuan pekerjaan yang dapat dipisahkan dari yang lain.

3. Biasanya volume pekerjaan besar dan hubungan antar aktifitas kompleks.

Heizer dan Render (2005) menjelaskan bahwa proyek dapat didefinisikan sebagai sederetan tugas yang diarahkan kepada suatu hasil utama. Menurut Akbar (2002) : Kegiatan proyek - dalam proses mencapai hasil akhirnya dibatasi oleh anggaran, jadwal, dan mutu yang harus dipenuhi - dibedakan dari kegiatan operasional, hal tersebut karena sifatnya yang dinamis, nonrutin, multikegiatan dengan intensitas yang berubah-ubah, serta memiliki siklus yang pendek. Dalam Meredith dan Mantel (2006) dikatakan bahwa "The project is complex enough that the subtasks require careful coordination and control in terms of timing, precedence, cost, and performance." Menurut Yamit (2000), setiap pekerjaan yang memiliki kegiatan awal dan memiliki kegiatan akhir, dengan kata lain setiap pekerjaan yang dimulai pada waktu tertentu dan direncanakan selesai atau berakhir pada waktu yang telah ditetapkan disebut proyek.

Berdasarkan pengertian proyek di atas, ciri-ciri proyek antara lain :

1. Memiliki tujuan tertentu berupa hasil kerja akhir.

2. Sifatnya sementara karena siklus proyek relatif pendek. 
3. Dalam proses pelaksanaannya, proyek dibatasi oleh jadwal, anggaran biaya, dan mutu hasil akhir.

4. Merupakan kegiatan nonrutin, tidak berulangulang.

5. Keperluan sumber daya berubah, baik macam maupun volumenya

Critical Path Method (CPM) is a procedure for using network analysis to identify those tasks which are on the critical path: ie where any delay in the completion of these tasks will lengthen the project timescale, unless action is taken. (Critical Path Method (CPM) adalah prosedur yang menggunakan analisis jaringan untuk mengidentifikasi tugas-tugas yang berada di jalur kritis: yaitu di mana setiap keterlambatan dalam penyelesaian tugas-tugas akan memperpanjang skala waktu proyek, kecuali diambil tindakan.)

Menurut Santiago \& Desirae Magallon dalam seminar VDC, 2009: The Critical Path Method or Critical Path Analysis, is a mathematically based algorithm for scheduling a set of project activities. (Critical Path Method) atau Critical Path Analysis, adalah algoritma matematis didasarkan untuk penjadwalan serangkaian kegiatan proyek.)

Menurut Samuel L. Baker, 2004: The Critical Path Method (CPM) is one of several related techniques for doing project planning. CPM is for projects that are made up of a number of individual activities. If some of the activities require other activities to finish before they can start, then the project becomes a complex web of activities. Critical Path Method (CPM) adalah salah satu dari beberapa penggabungan teknik untuk melakukan perencanaan proyek. CPM untuk proyek-proyek yang terdiri dari sejumlah kegiatan individu. Jika beberapa kegiatan memerlukan kegiatan lain untuk menyelesaikan sebelum mereka dapat memulai, maka proyek menjadi kompleks jaringan kegiatan.)

Jika ditarik kesimpulan dari beberapa definisi di atas, maka yang dimaksud Critical Path Method (CPM) adalah teknik yang digunakan untuk melakukan perencanaan proyek menggunakan algoritma matematis.

Kelebihan dan Kekurangan Critical Path Method (CPM)

Kelebihan yang dimiliki metode Critical Path Method (CPM) yaitu:

1. Untuk penjadwalan, pemantauan, dan pengendalian proyek.

2. Seorang manajer proyek dapat menentukan tanggal yang sebenarnya untuk setiap kegiatan dan membandingkan apa yang seharusnya terjadi dengan apa yang sedang terjadi dan reaksinya.Kegiatan dan hasilnya dapat ditampilkan sebagai jaringan.

3. Menampilkan dependensi untuk membantu penjadwalan.

4. Melakukan evaluasi kegiatan yang dapat berjalan sejajar satu sama lain.

5. Menentukan slack dan float.

6. Banyak digunakan dalam industri.

7. Dapat menentukan beberapa jalur yang sama penting.

8. Menentukan durasi proyek, yang meminimalkan jumlah biaya langsung dan tidak langsung.

9. Memberikan tampilan grafis dari alur kegiatan sebuah proyek.

10.Menunjukkan alur kegiatan mana saja yang penting diperhatikan dalam menjaga jadwal penyelesaian proyek.

Sedangkan kekurangan yang dimiliki metode Critical Path Method (CPM) yaitu :

1. Dapat menjadi rumit dan meningkatkan kompleksitas untuk proyek yang lebih besar.

2. Tidak menangani penjadwalan personil atau alokasi sumber daya.

3. Jalur kritis tidak selalu jelas dan perlu dihitung cermat.

4. Memperkirakan waktu penyelesaian kegiatan bisa sulit.

Metode jaringan kerja diperkenalkan menjelang akhir dekade 1950-an, oleh suatu tim engineer dan ahli matematika dari perusahaan DuPont bekerja sama dengan Rand Corporation, dalam usaha mengembangkan suatu sistem kontrol manajemen. Jaringan kerja berguna untuk 
menyusun urutan kegiatan proyek yang memiliki sejumlah besar komponen dengan hubungan ketergantungan yang kompleks, membuat perkiraan jadwal proyek yang paling ekonomis, mengusahakan fluktuasi minimal penggunaan sumber daya.

Menurut Gray (2000), jaringan kerja adalah framework untuk sistem informasi proyek yang

akan digunakan oleh manajer proyek untuk $\mathrm{m}$ embuat keputusan yang berhubungan dengan waktu, biaya, dan performance. Jaringan kerja memberikan waktu dimana kegiatan dapat dimulai dan diselesaikan dan kapan kegiatan dapat ditunda.

Menurut Soehatto (1999), CPM (Critical Path Method) dan PERT (Project Evaluation and Review Technique) memakai teknik penyajian secara gratis dengan memakai diagram anak panah, lingkaran serta kaidah-kaidah dasar logika ketergantungan dalam menyusun urutan kegiatan. Menurut Mulyono (2004), model jaringan CPMIPERT tersusun atas dua komponen utama, yaitu titik-titik (nokhta/ lingkaran) dan garis-garis ( cabang/ anak panah). Garis menunjukkan jenis kegiatan dari suatu proyek, sementara titik menunjukkan awal atau akhir suatu kegiatan atau biasa dinamakan events. Model jaringan juga menunjukkan precedence relationship antara kegiatan-kegiatan.

Ada suatu aturan dalam membuat model jaringan CPMIPERT, yaitu bahwa dua atau lebih kegiatan tak dapat secara serentak berawal dan berakhir pada lingkaran yang sama. Maka permasalahan tersebut dapat diatasi dengan suat dummy activity.Suatu dummy activity digambar kan dengan anak panah terputus dan disisipkan pada jaringan itu untuk menunjukkan suatu precedence relationship. Suatu dummy activity tidak memakan waktu dan sumber daya, jadi waktu kegiatan dan biaya sama dengan nol. Kegiatan dummy dapat juga digunakan untuk menyusun suatu jaringan yang agar hubungan logikanya menjadi benar.

Sasaran utama analisis CPM/PERT adalah menentukan waktu terpendek yang diperlukan untuk menyelesaikan suatu proyek atau menentukan waktu yang diperlukan untuk suatu critical path, yaitu jalur waktu terlama. Kegiatan kegiatan yang dilewati critical path dinamakan kegiatan kritis. Keterlambatan penyelesaian salah satu kegiatan ini akan menyebabkan keterlambatan penyelesaian proyek, karena itu kegiatan-kegiatan kritis perlu diawasi secara serius. Jika pengambil keputusan bermaksud mempercepat penyelesaian proyek, maka ia perlu memperpendek satu atau beberapa waktu kegiatan kritis.

Menurut Soeharto (1999), CPM (Critical Path Method) menggunakan satu angka estimasi dan dalam praktek lebih banyak dipergunakan oleh kalangan industri atau proyek-proyek engineering konstruksi. Menurut Levin (1999), Jika waktu dapat diperkirakan dengan cukup tepat dan biayabiaya dapat dihitung sejak semula, maka lebih menguntungkanjika dipergunakan CPM.

\section{METODOLOGI}

Kegiatan pelatihan Manajemen Proyek dengan Metode Critical Path Method (CPM) ini dilaksanakan di kantor PT. Niromukti Airtech Indonesia. Kegiatan abdimas ini dilakukan dengan metode penyuluhan, diskusi, dan juga tanya jawab oleh para karyawan.

1. Tahapan Pelaksanaan

Kegiatan pengabdian masyarakat ini dimulai dari bulan Maret 2019 sampai dengan Mei 2019, dengan tahapan sebagai berikut:

a. Melakukan survey ke PT. Niromukti Airtech Indonesia dan diskusi dengan Direktur PT. Niromukti Airtech Indonesia mengenai materi yang sesuai untuk karyawan mengenai manajemen proyek.

b. Proses persiapan sosialisasi Manajemen Proyek dengan Metode Critical Path Method (CPM) kepada karyawan PT. Niromukti Airtech Indonesia.

c. Melakukan penyuluhan kepada siswa-siswi dengan metode diskusi dan tanya jawab 
2. Pelaksanaan Kegiatan

Kegiatan abdimas ini dilakukan atas dasar izin dari pihak perusahaan, yaitu PT. Niromukti Airtech Indonesia. Kegiatan abdimas ini diawali dengan observasi lapangan untuk mengetahui target kegiatan, kondisi karyawan yang akan diberikan pelatihan dan menyusun rancangan kegiatan yang akan dilakukan.

Kegiatan berikutnya adalah melakukan penyuluhan sosialisasi mengenai Manajemen Proyek dengan Metode Critical Path Method (CPM) kepada karyawan PT. Niromukti Airtech Indonesia dengan menggunakan infocus, para karyawan dapat melihat, dan bisa memahami pelatihan yang disampaikan oleh Team Abdimas. Kegiatan dilaksanakan di dalam salah satu ruangan di PT. Niromukti Airtech Indonesia. Semua karyawan memperhatikan pelatihan ini karena sangat berguna untuk menambah wawasan bagi karywan PT. Niromukti Airtech Indonesia supaya dapat membuat penjadwalan proyek dengan baik sehingga pengerjaan proyek dapat tepat waktu, juga memahami konsep CPM dengan baik dan mengaplikasikannya dalam menjalankan suatu proyek.

Berdasarkan hasil pelatihan yang telah dilaksanakan kepada para karyawan, maka dilakukan sesi tanya jawab antara karyawan dengan team abdimas. Hasil yang kami amati bahwa para karyawan sangat antusias dengan materi yang disampaikan, hal ini terbukti dengan banyaknya pertanyaan yang diajukan oleh para karyawan kepada team abdimas.

\section{HASIL DAN PEMBAHASAN}

Kegiatan pelatihan Manajemen Proyek dengan Metode Critical Path Method (CPM) untuk menambah wawasan memahami konsep CPM dengan baik dan mengaplikasikannya dalam menjalankan suatu proyek kepada para karyawan PT. Niromukti Airtech Indonesia, yang dilakukan oleh team abdimas dari Universitas Indraprasta PGRI Jakarta yang beranggotakan 3 (tiga) orang. Kegiatan dilaksanakan terhadap para karyawan di ruang kantor. Kegiatan ini diawali dengan observasi kepada mitra tersebut pada bulan maret 2019 untuk mengumpulkan informasi, mengenai materi yang sesuai untuk karyawan mengenai manajemen proyek.

Di bulan Maret minggu pertama, tim abdimas melakukan pembuatan materi untuk memudahkan penyuluhan pembelajaran. Pada bulan april minggu keempat melaksanakan kegiatan pelatihan. Berdasarkan sosialisasi kegiatan pelatihan ini, diperoleh hasil sebagai berikut: [1]. Para karyawan sangat antusias dengan materi yang disampaikan oleh team abdimas; [2]. Para Karyawan mendapatkan wawasan mengenai bagaimana membuat penjadwalan proyek dengan baik sehingga pengerjaan proyek dapat tepat waktu, juga memahami konsep CPM dengan baik dan mengaplikasikannya dalam menjalankan suatu proyek.

Kegiatan pelatihan Manajemen Proyek dengan Metode Critical Path Method (CPM) yang dilakukan bermanfaat sekali bagi karyawan PT. Niromukti Airtech Indonesia, dengan pelatihan ini diharapkan bisa menambah wawasan dan pengetahuan dari masing-masing peserta. Dukungan dari direktur PT. Niromukti Airtech Indonesia yang telah menginstruksikan para karyawan agar serius dan fokus dalam mengikuti kegiatan ini patut diapresiasi, mulai dari perkenalan, penyampaian materi sampai akhir pelatihan.

Dengan penambahan wawasan / pengetahuan mengani Manajemen Proyek dengan metode CPM, sehingga secara keseluruhan proses kegiatan abdimas dapat terlaksana dengan baik. Dapat disimpulkan bahwa kegiatan ini dapat meningkatkan kemampuan, pengetahuan, wawasan dan motivasi para karyawan PT. Niromukti Airtech Indonesia dalam melaksanakan pekerjaannya. 


\section{PENUTUP}

Simpulan

Berdasarkan hasil pelaksanaan pengabdian pada masyarakat yang telah dilaksanakan di PT. Niromukti Airtech Indonesia, maka dapat disimpulkan hal-hal sebagai berikut:

Para Karyawan mendapatkan wawasan mengenai bagaimana membuat penjadwalan proyek dengan baik sehingga pengerjaan proyek dapat tepat waktu, juga memahami konsep CPM dengan baik dan mengaplikasikannya dalam menjalankan suatu proyek

Kegiatan abdimas ini membutuhkan dukungan semua pihak, khususnya dari pihak mitra yaitu Direkur PT. Niromukti Airtech Indonesia beserta karyawannya, dan juga dari team abdimas Universitas Indraprasta PGRI sehingga pelaksanaan abdimas berjalan dngan baik.

\section{DAFTAR PUSTAKA}

Mercier, Arther G and Nunnaly, Roy S. 1965. The Critical Path Method : It's Fundamentals. NPS Public. California

P. Stelth. 2009. Project's Analysis Through CPM .European Union Journal. Inles International University.

Samuel L. Baker, Ph.D. "Critical Path Method (CPM)"

(http://hspm.sph.sc.edu/COURSES/J716/ CPM/CPM.html).University of South Carolina, Health Services Policy and Management Courses 